\title{
Design and Validation of a Bracket using a Laser Scanner, Topology Opti- mization, and a 3-D Printer
}

\section{Dr. Luis E. Monterrubio, Robert Morris University}

Luis E. Monterrubio joined the Robert Morris University Engineering Department as an Assistant Professor in the Fall of 2013. He earned his B.Eng. from the Universidad Nacional Autónoma de México, his M.A.Sc. from the University of Victoria, Canada, and his Ph.D. from the University of Waikato, New Zealand. All degrees are in Mechanical Engineering and both M.A.Sc. and Ph.D. studies are related with vibrations. After his Ph.D. he worked at the University of California, San Diego as postdoctoral fellow in the area of bioacoustics. He teaches dynamics, machine design, numerical methods and finite element methods. He has worked for the automotive industry in drafting, manufacturing, testing (internal combustion engines-power, torque and exhaust emissions, vibration fatigue, thermo-shock, tensile tests, etc.), simulations (finite element method), and as a project manager (planning and installation of new testing facilities). 


\section{Design and validation of a bracket using laser scanner, topology optimization and a 3D printer}

\section{Introduction}

Laser scanners, topology optimization through the use of commercial finite element method (FEM) software and 3D printers have become common tools to reverse engineer and develop lighter products in the industry. Reverse engineering is a process in which the starting point of a new design starts with an existing design [1]. These tools were incorporated into a design course in a Mechanical Engineering program to design and validate a lighter version of a bracket.

3D Laser scanners are used to obtain the geometry of existing parts determining the position of a scanned area by sensing the reflection of a laser on a surface taking into account the period of return of the light ray and the angle of impact [2]. The points obtained during the scanning process are used to form surfaces that can be stored in many digital formats including .IGES files which can be opened in a Computer Aided Design (CAD) software or .STL which is commonly used to 3D print a part. Topology optimization is a methodology to derive an optimal material distribution for a design under given loads and boundary conditions [3]. In a stress analysis, this process reduces or eliminates the mass of a structure in areas where the level of stress is low. This methodology was first implemented in a commercial finite element method software in 1994 by Altair - OptiStruct. Many commercial software have now different features to lighten new products. The 3D printing technique is an additive manufacturing process consisting in depositing layers that allows manufacturing parts that due to the complexity of their geometry are impractical to produce by either plastic injection or casting of metals [4].

With these tools students will be able to reverse engineer a bracket that will be able to withstand the load applied to the original bracket and even though the maximum level of stress will increase in their design, the maximum level of stress will be kept below the yield strength of the material. Written reports and quizzes were used in addition to students' optimized designs to assess student outcomes. These activities are part of the FEM course taught by the author of this work. The activities in this work can be part of other courses such as reverse engineering or rapid prototyping courses, but it is probably better if students already have learnt at least the basics of the FEM.

A different bracket model has been used each semester. Most of these brackets are similar in geometry to brackets that support the engine of a car. But topology optimization can be carried out on any type of structure. 


\section{Reverse engineering of a bracket}

In this work the following labs are proposed to design a lighter version of a known bracket:

a) obtain the geometry of a bracket using a laser scanner,

b) carry out a topology optimization to lighten the design of a bracket, checking that the new lighter design will not fail under a specified load, and

c) experimental test using a universal machine to validate stress and topology optimization carried out using commercial FEM software.

\section{Laser scanner}

In this course a laser scanner from Faro Technologies shown in Figure 1 was used to capture a 3D model of a bracket. Figure 2 shows a student scanning a bracket using a laser and Geomagic (software). It is also worth mentioning that this arm has also capabilities similar to a measure coordinate machine (CMM) that allows to use the arm for quality control measurements. The arm can be used with either Geomagic Qualify or Geomagic Studio. This allows users to create CAD models from 3D scan data or check measurements for quality control.

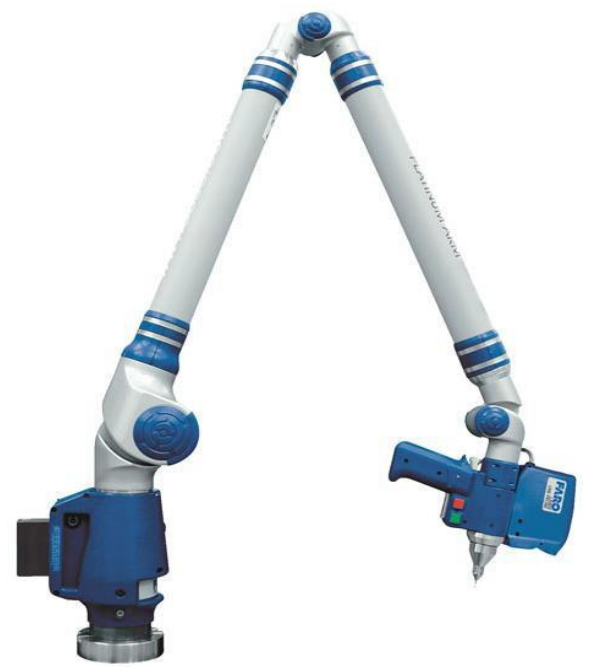

Figure 1. Laser scanner

Previous works presented at ASEE conferences using laser scanners include the work in references [5-6]. In [5] Eslami presented a reverse engineering example using a laser scanner to obtain the geometry of a bracket. Then MasterCam for SolidWorks and a Computer Numerical Control (CNC) milling machine were used to manufacture a duplicate of the original bracket. In [6] Krivoniak and Sirinterlikci used a laser scanner to obtain the geometry an ankle-foot orthosis (AFO) for a specific patient. An AFO is an L-shaped orthotic device that provides support to the lower leg and foot.

Similarly, in this work a laser scanner is used to obtain the geometry of a bracket. Students need a little bit of practice using the laser scanner before becoming efficient in its use. This is because during a scanning operation the laser scanner must be kept four inches away from the surface to be scanned. After scanning the geometry of the bracket, students were asked to improve the model in Geomagic using tools such as: Sandpaper that allows smoothing out bumps and spikes; Decimate Polygons that reduces polygon counts by deleting unnecessary 
items; Shell that creates a shell (a body with no thickness); and Fill Holes that fills in holes of the model, etc. Once these tools are run the model is saved in .STL format to be used with a 3D printer to produce a model of the original design and as an .IGES file that can be imported to a CAD software to complete the solid model needed to set up a FEA in Abaqus.

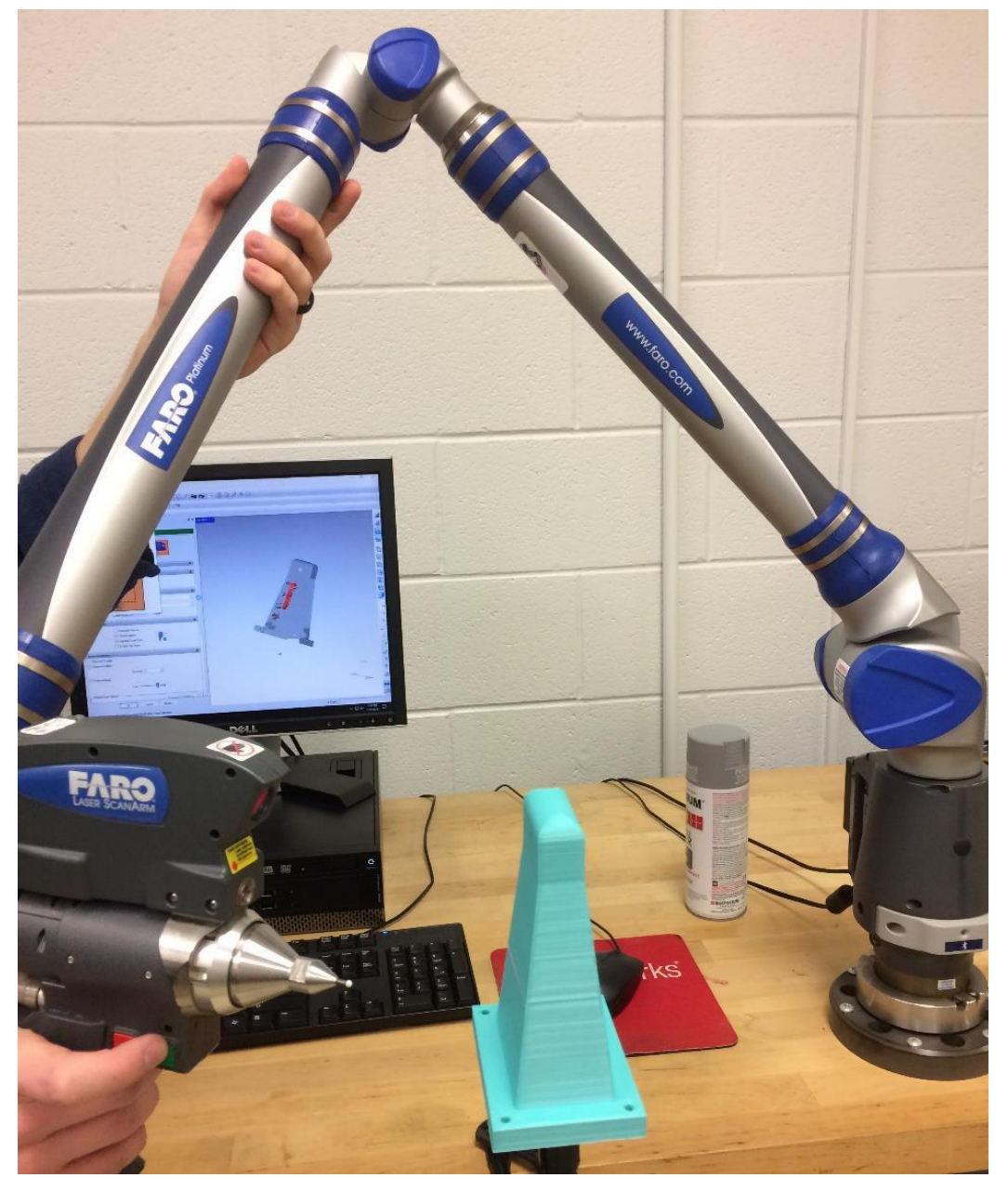

Figure 2. Scan of a bracket using a laser scanner and Geomagic

\section{Topology optimization}

The general procedure to set up a static analysis in Abaqus starting with an .IGES file that contains the model of the structure to be analyzed is
a) Import geometry
b) Create material,
c) Create section and assign section to the structure
d) Create an instance, seed and mesh instance
e) Create a static, general step
f) Apply boundary conditions and load.
g) Create and submit the job
h) Post-process 
The model and the results of one of the proposed brackets are shown in Figure 3.

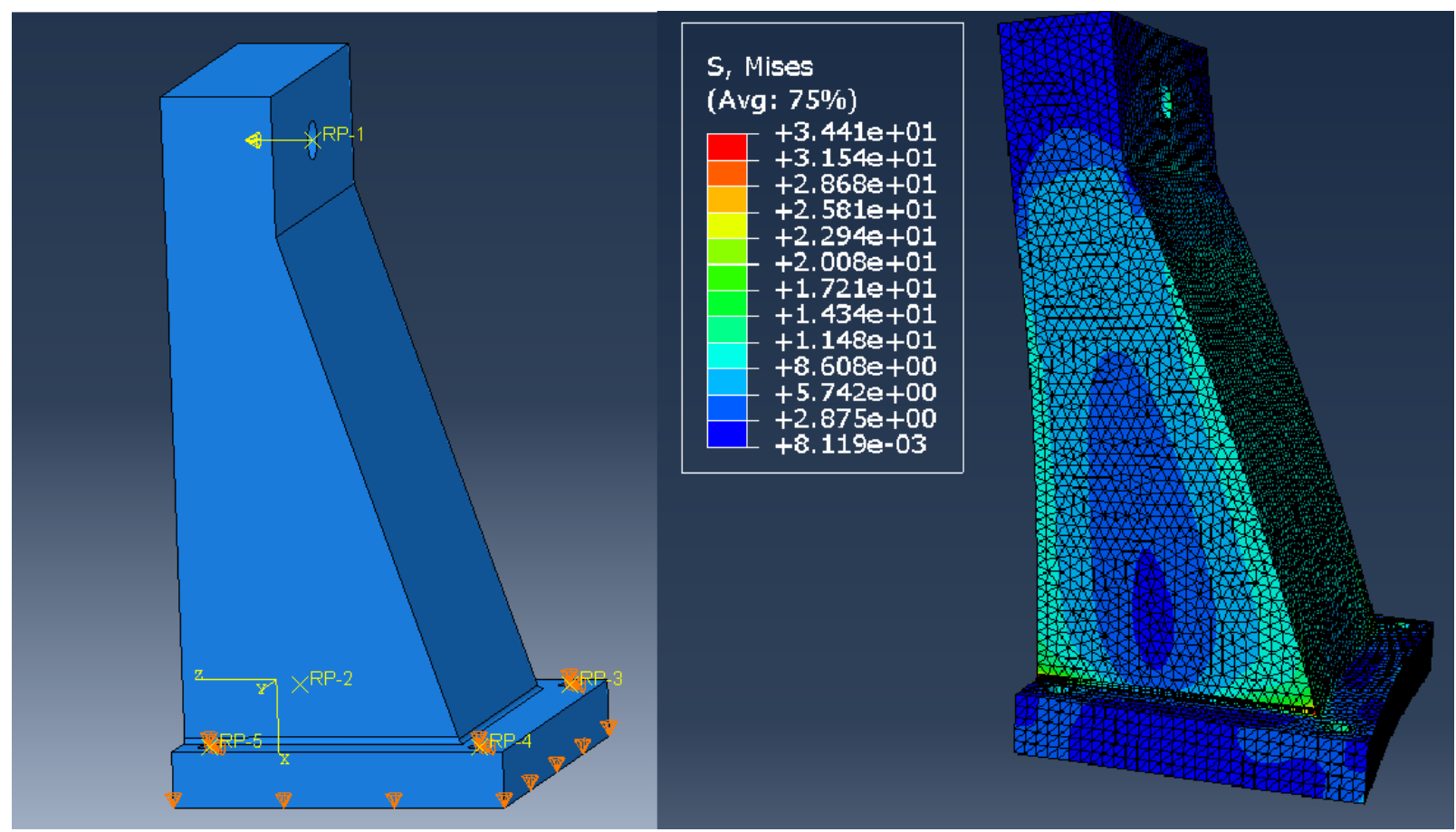

Figure 3. (Left) model of a bracket with boundary conditions defined at the bottom of the bracket constraining vertical motion and all three translations at the four reference points. Reference points are the master nodes of rigid bodies containing all nodes on the holes. The load is applied on the vertical surface at the top of the bracket in the direction given by the arrow. (Right) results of the static stress analysis.

The topology optimization problem can be presented in a more formal way as the solution for the minimum (top down) or maximum (bottom up) value of a function $f(x)$ and its related variable vector $x=\left(x_{1}, \ldots, x_{n}\right) \in I R n$. Then the optimization problem can be expressed as [3]:

(x) minimize this objective function (in Abaqus this is the strain energy for this problem. The idea is to optimize the maximum stiffness)

$h(x)=0, j=1, \ldots, n_{h}$ equality constrains (in Abaqus this will be the physical bounds)

$(x) \leq 0, k=1, \ldots, n_{g}$ inequality constraints

$x_{i}{ }_{i} \leq x_{i} \leq x_{i} u, i=1, \ldots$, design variables (in Abaqus this can be symmetry, manufacturing)

where

$n_{h}$ : number of equality constraints

$n_{\mathrm{g}}$ : number of inequality constraints

$n$ : number of design variables

$x_{i} l$ : lower bound of the design variable $x_{i}$

$x_{i}{ }_{i}^{u}$ : upper bound of the design variable $x_{i}$

The additional steps, after the static stress analysis, to set up a topology optimization in Abaqus 
a. Create an Optimization task - Topology optimization

b. Create Strain_Energy design response -single-term, select the whole model

c. Create Volume design response -single-term, select the whole model

d. Create objective function Strain_Energy

e. Create optimization constraints. Defining a fraction of the initial value $=0 . X$

f. Create the Geometric Restrictions - frozen area, better if element set is created to define geometric conditions.

g. Run the analysis

h. Combine results, and extract a .STL file smoothing the surface of the bracket.

Students are given the task to minimize the mass of the bracket as much as possible but keeping the maximum level of stress below the yield strength of SLA equal to $80 \mathrm{MPa}$. Students can attempt to reduce the mass in different percentages and including different sets of elements in the frozen regions of the bracket that are forced to be kept in the final design. Figure 4 below shows an example of the optimized bracket.

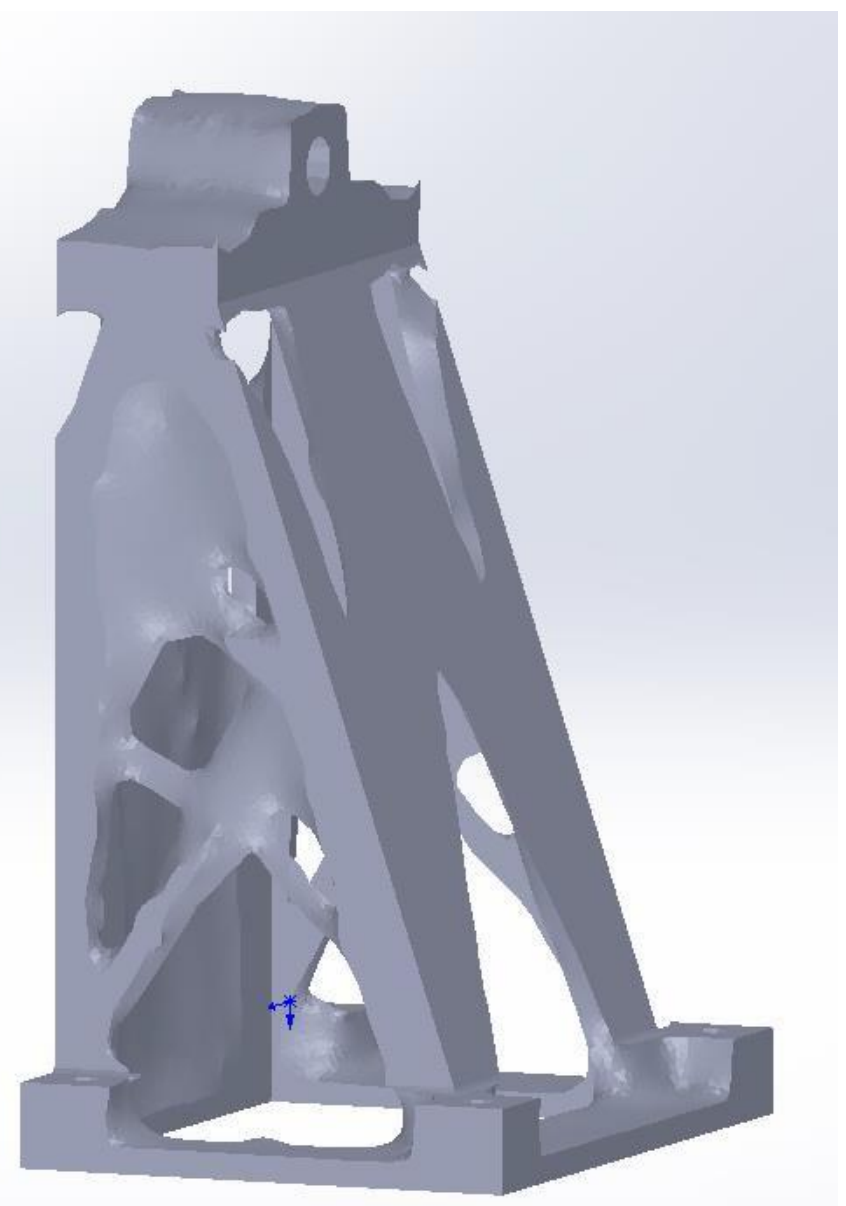

Figure 4. Optimized design of the bracket with a reduction of 55\% of its mass. 


\section{Experimental test of original and optimized 3D printed brackets}

After the brackets have been scanned and a new optimized version of the bracket has been created using topology optimization an experimental test in a universal machine such as the one shown in Figure 5 is performed to validate the FEA results. It is important for students to understand that it is only the experimental results what will give the green light to a production line. On the other hand, if parts are 3D printed and the finishing is not good, defects will create stress concentration areas which will diminish the strength of the part.

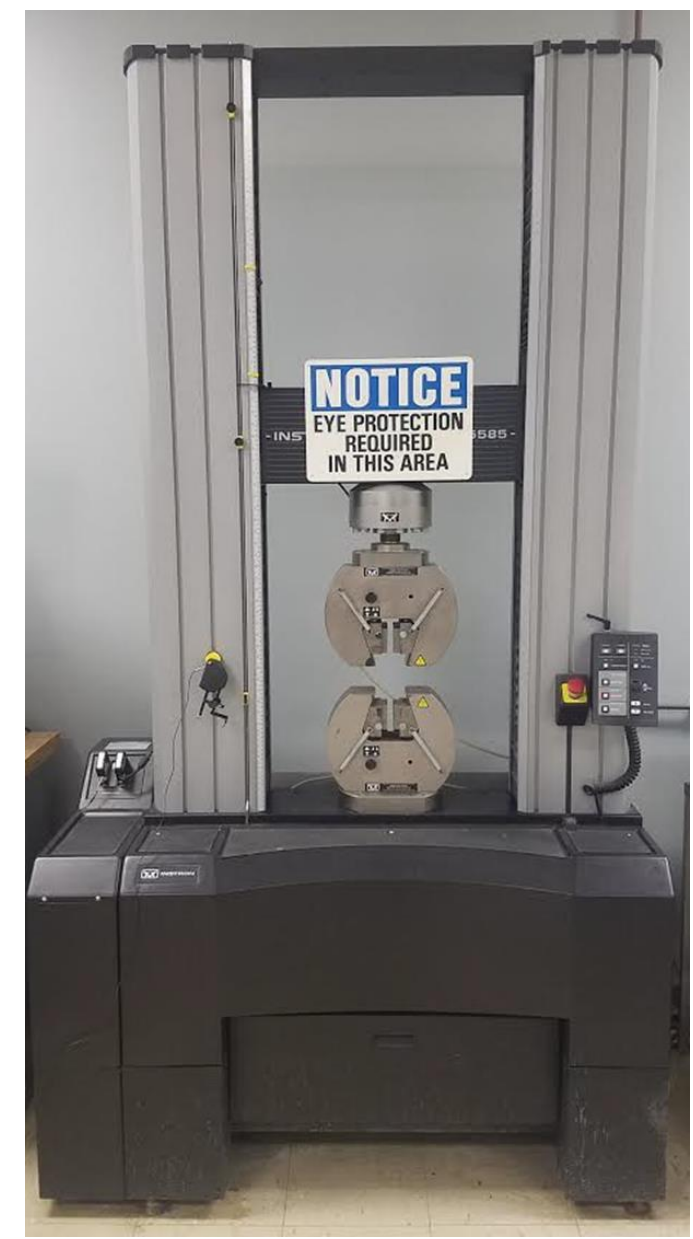

Figure 5. Universal machine

\section{Results}

Students are assessed with the following deliveries.

Laser scan (team work)

a) Quality of their.STL and .IGES files produced with Geomagic

b) Description of the procedure used to create their .STL and .IGES files including tools used in Geomagic such as: sandpaper; decimate polygons; fill holes, etc. 
Survey (individual work)

c) Were you familiar with laser scanning before this course?

d) Was the laser scanning lab interesting?

e) Write additional uses of laser scanners. Look in the internet for more uses of laser scanners. Please write with your own words

Topology optimization (individual work)

f) The percentage of mass you were able to remove from the original design, Abaqus file must be presented. Each student must have a different solution.

g) Description of the selected frozen areas.

h) Describe areas with the highest level of stress in your results for the original and optimize versions of the bracket (plot your model as clearly as possible)

i) How many iterations did you need to achieve your best result?

j) Was the topology optimization Abaqus lab interesting? What did you learn?

\section{Experimental test}

k) Description of experimental work

1) Were the experimental results close to FEA? Determine the difference in percentage.

m) Write your conclusions of the whole reverse engineering exercise.

\section{Assessment of the activities}

The rubric used to assess the work of the students is given in Table 1 below

Table 1. Rubric of the hands-on components of the course.

\begin{tabular}{|c|c|c|c|}
\hline Component & Sophisticated & Competent & Not yet Competent \\
\hline $\begin{array}{l}\text { Laser } \\
\text { scanner }\end{array}$ & $\begin{array}{l}\text { Students were able to scan } \\
\text { the bracket without holes, } \\
\text { use some of Geomagic } \\
\text { tools improve the model } \\
\text { and produce an .STL and } \\
\text {.IGES files }\end{array}$ & $\begin{array}{l}\text { Students were able to scan } \\
\text { the bracket without holes, } \\
\text { but better use of Geomagic } \\
\text { tools could improve the } \\
\text { model. Students produced } \\
\text { an .STL and .IGES files }\end{array}$ & $\begin{array}{c}\text { Students scanned the } \\
\text { bracket but left holes an } \\
\text { imperfections ion the } \\
\text { surfaces. Students didn't } \\
\text { produce. STL and .IGES } \\
\text { files }\end{array}$ \\
\hline $\begin{array}{c}\text { Topology } \\
\text { optimization }\end{array}$ & $\begin{array}{l}\text { The volume of the } \\
\text { optimized bracket was } \\
\text { reduced in an acceptable } \\
\text { percentage. } \\
\text { Description of the process } \\
\text { is clear } \\
\text { Frozen areas were chosen } \\
\text { in a smart way } \\
\text { Area with highest level of } \\
\text { stress is identified clearly }\end{array}$ & $\begin{array}{l}\text { The volume of the } \\
\text { optimized bracket was } \\
\text { reduced, but it can be } \\
\text { reduced even more. } \\
\text { Description of the process } \\
\text { is brief }\end{array}$ & $\begin{array}{c}\text { The reduction of the } \\
\text { volume of the optimized } \\
\text { bracket was not } \\
\text { significant. } \\
\text { Description of the process } \\
\text { is not clear. } \\
\text { Area with highest level of } \\
\text { stress is not identified } \\
\text { clearly }\end{array}$ \\
\hline $\begin{array}{l}\text { Experimental } \\
\text { Test and } \\
\text { Conclusions }\end{array}$ & $\begin{array}{c}\text { Experimental work is } \\
\text { properly described. } \\
\text { Results are correct. }\end{array}$ & $\begin{array}{l}\text { Experimental test isn't } \\
\text { properly described or } \\
\text { results are incorrect. }\end{array}$ & $\begin{array}{c}\text { Both experimental work is } \\
\text { not properly described and } \\
\text { results are incorrect. }\end{array}$ \\
\hline
\end{tabular}


The distribution of the grades of these labs during the last year are $84.6 \%$ of students had a grade between $90 \%$ and $100 \%$ (sophisticated), $7.7 \%$ received a grade between $80 \%$ and $89 \%$ (competent) and 7.7 received a grade lower than $79 \%$.

\section{Comments and Conclusions}

Through these labs it is ensured that students understand the basics of the use of a 3D laser scanner, Topology optimization, 3D printing and the importance of correlating FEA with experimental tests. Students enjoy hands-on activities that allow them to understand the concepts covered in the classroom. While working with 3D printers using SLA material, something to take into account is the quality of the 3D printers. Our original 3D printer had a very good quality, but unfortunately broke down a year ago. The new 3D printers have a very rough finishing and can be the reason for failure with loads a lot smaller than expected from results in FEA. For this reason, we had to pay more attention to the direction in which brackets were 3D printed and to the minimum thickness of the bracket. These activities can of course be used with 3D printers for metals or composite materials.

Students found the activities useful and interesting. Most of the students never used a laser scanner nor did a topology optimization before. Thus, students added knowledge and skills that will help them to increase the quality of their designs when they join the workforce. Students have also understood that it is only through physical testing that they can validate their designs before starting a production line. The results showed that stresses almost increased inversely proportional with the decreased in volume. Adding ribs to the brackets can help to reduce stresses with marginal increment of volume.

\section{References}

[1] Vijaya Ramnath, B., Elanchezhian, C., Jeykrishnan, J., Ragavendar, R., Rakesh, P.K., Sujay Dhamodar, J., Danasekar, A., Implementation of Reverse Engineering for Crankshaft Manufacturing Industry, Materials Today: Proceedings, Vol. 5, Issue 1, 2018, pp. 994-999, ISSN 2214-7853,

[2] Tóth, T., Živčák, J. A Comparison of the Outputs of 3D Scanners, Procedia Engineering, Vol. 69, 2014, pp. 393-401, ISSN 1877-7058.

[3] Tyflopoulos, E.,Tollnes Flem, D., Steinert, M., Olsen, A., State of the Art of Generative Design and Topology Optimization and Potential Research Needs, NordDesign 2018, August 14-17, 2018 Linköping, Sweden.

[4] Holzmond, O., Li, X., In Situ Real Time Defect Detection of 3D Printed Parts, Additive Manufacturing, Vol. 17, 2017, pp. 135-142.

[5] Eslami, A. M., Integrating Reverse Engineering and 3D Printing for the

Manufacturing Process, 2017 ASEE Annual Conference \& Exposition, June 25 - 28, 2017, Columbus, Ohio.

[6] Krivoniak, A., Sirinterlikci, A., 3D Printed Custom Orthotic Device Development: A Student-driven Project, 2017 ASEE Annual Conference \& Exposition, June 25 - 28, 2017, Columbus, Ohio. 